\title{
THE INVENTION OF HUMAN: BIOLOGY AND TECHNOLOGY AS EXISTENCE
}

Yonathan Listik

Tel Aviv University

\begin{abstract}
How does the body and the mechanism of life connect to the notion of existence? Using what Stiegler terms by the invention of the human as the basic question to deal with, I am seeking, in this article, how I can take advantage of Jonas to talk about the human condition. That is, using Stiegler's idea that human existence is rooted in its mechanisms/technology, I intend to explore how Jonas' theories on the relation between biology and existence make room for a theory of the human condition that does not demand an absolute truth but is conditioned on existence itself instead. The goal is not to argue what Stiegler would say about Jonas. This article is an attempt to answer the ontological question of existence, such as Stiegler proposes it, using the same arguments proposed by Jonas and then extract a theory of life and its senses from this.
\end{abstract}

Keywords: Evolution. Technology. Metabolism. Invention. Human

$$
* * *
$$

\section{The meaning of invention:}

I would like to begin with a quote from Popper: "I have come to the conclusion that Darwinism is not a testable scientific theory, but a metaphysical research programme - a possible

\footnotetext{
${ }^{1}$ Master of Philosophy, invited Professor at Federal University of São Paulo. Email listiky@mail.tau.ac.il.
} 
framework for testable scientific theories" (POPPER, 1976, p.168, italics in the original). I would not wish to explore Popper's theory, but I believe that he - as a respected scientist and philosopher - illustrates my underlying argument that science has a limited scope on life: sciences explores some aspects of life but it leaves vital elements in the shadow. Simply put, science is not sufficient to explain the phenomenon of life. This does not mean that it is useless or irrelevant to the discussion. When Popper argues that Darwinism ${ }^{2}$ is metaphysical, I understand he is arguing that scientific method is not sufficient in order to explain the phenomenon of life. The phenomenon demands that, beyond the factual evidence and possible experiments, theory provides meaning.

I believe this is precisely the starting point for a possible discussion on the human: in order to properly think about the human condition, it is neither sufficient to just describe the functioning of human bodies nor reduce him to his spirit/mind/conscience. In this sense, it is necessary to explore the way Biology and technology (mechanism of life) are not opposite to life but rather the actual realization of it. It is essential to show that life/freedom is not the space or elbowroom within a determined condition, but, instead, conditions are always living conditions. What I mean is that conditions are the actual realization of existence.

The invention of the human is not the question regarding who causes the human existence. It is not concerned with revealing the agency causing 'the human' to come out of thin air. Instead, it concerns the conditions of realization of what we denominate the human, i.e., the circumstances under which a human is human. Thus, is it possible to talk about the human under what situations? What are the factors that allow the human to come into existence? From my

\footnotetext{
${ }^{2}$ Since I will not explore Popper's theory in depth, I ask you to consider Darwinism simply to include notions as natural selection and evolution.
}

\section{Blucher}


perspective, Stiegler's best development of this question is in Time and Technics. In this text, he does not ask about the invention of the human as the creation of the human- in any of this term's senses: god's creation, the creation of the human in discourse, etc. Instead, he inquires upon a theory concerning the possibility of human coming into existence through its technological mechanism. That is, the relationship between human evolution/development as a body and the evolution/development of human as a being. Shortly, it is a question of human being ${ }^{3}$ as the question of being human.

The central issue is: how is evolution even possible? If the question here is how the human came to be, the implicit point is that it became human or, as it is commonly said, evolved into the human. Yet, evolution is not self-evident since considering the mechanistic/scientific perspective, there is no space for freedom or mistakes that cause change. In a fully determined mechanism, there cannot be any unexpected consequences. If evolution depends on mutation, and mutation is a mistake/change, how is it coherent with a mechanical structure?

Evolution is the central concept precisely because it epitomizes the victory of materiality over idealism, while marking the insufficiency of materiality to explain life and, therefore, the necessity of further explanation: "It may be taken for granted that a metaphysical point of view is not only the effect but also the cause of scientific development" (JONAS, 1966, p. 70, in clear dialogue with Popper's quote). Evolution shows that human existence is neither pure conscience/ mind/spirit locked in a body (as in the argument that there is a relation between life and the mechanism of the body) nor pure mechanism that explains life. Biology is not Physics, it does not

\footnotetext{
${ }^{3}$ As in the common nomenclature used in biological discussions
} 
have absolute laws, but rather it adapts. The laws of Physics do not adapt to reality, they neither change it nor form a contingent picture of reality where under different conditions we would expect different laws. Notwithstanding, it is impossible to think of Biology without considering the development of living things and the constant adaptations/changes in ecosystems ${ }^{4}$.

Thereby, things are neither utterly determined from the start nor flows towards a common/reasonable end (telos), evolution demands the question of contingency and freedom within material determination. Taking evolution seriously is attempting to detect the way mistakes and randomness adapt to the environment and create the living body that interacts (maybe not perfectly but sufficiently well) with the nonliving world. It demands that one deliberates on the question of life through the concept of freedom (not necessarily choice) in order to fully grasp the movement of becoming imperative to life.

Hans Jonas elaborates this question in his book The Phenomenon of Life at the chapter Philosophical Aspects of Darwinism. In his text, he explores the problematic assumption that one can reduce existence to the mechanical functions of the body inasmuch as it does not fully explain life, let alone the invention of the human (described earlier in the text). In a sense, in order to consider life, Philosophy must set itself free from the Cartesian dualism. In fact, within the Cartesian picture, life has no place. If the body is just a mechanism as Descartes (and many after him) argues, life does not exist. It is not possible to satisfactorily reflect about life as long as mind and body are considered separable and possess no common measurement with each other. So as to think

\footnotetext{
${ }^{4}$ Here I purposely avoid the concept of "contingency" because, as I will try to explain, the freedom that we find in biology is not necessarily contingency despite the fact that the notion of "it could have been otherwise" plays a role here through my argument on technology.
} 
properly about the life, Jonas argues that body and mind must be taken into account. In other words, Jonas adds the aspect of life's freedom to the question of invention from within its condition. Without this movement into life, this 'choice' into life, there is no possible way to conceive the notion of humanity itself. If the question is then the concern for the meaning behind evolution, so it is essential to bear in mind the concept of life and movement whereby life is grounded. To put it simply, the issue does not regard the fully causal or chaotic but on the freedom within heredity, the possibility of change and development in a given situation. In his own metaphor, how to think the dynamics of constant 'throwing of the dices' where each throw is reliant on the other since it comes from the situation as much as it 'invents' a situation.

The text will explore how Stiegler's system fits in with aspects of Jonas' theory in order to form an image of humanity that copes with the problematics of thinking human existence as both physical and mental phenomena. The goal is not to argue how mind and body are reduced one to another, but argue that human existence is invariably realized in its presence in the world. Hence, it neither came-into-being from something exterior nor is reduced to its sheer mechanical materiality, it is/exists only by its actual/real presence as a body/thing instead. That is, the human Being is not considered then as a transcendental object (neither as ultimate spirit nor ultimate matter) but rather as the actual notion of human being in the full sense of the word.

\section{The question of technology:}

Stiegler, in Technics and Time, begins his argument with an essential question about 
technology: what is the relation between techne and life? As it is usually treated, one essentially opposes these two concepts making the question of life equivalent to the question of what is essential, what is the real, and the question of techne as regarding the contingent, what is technologically produced and could be otherwise. Life is not created, it just is what it is, on the other hand, techne results from an operation, it is an object of our actions or the means to it. Life is just the nature of things. According to this definition, the division is also temporary. Once humanity discovers the true essence of life, there would no longer be technology since we would identify 'what' and 'how' something is.

However, more importantly, implicit in the division there is an essential separation between objects of science and objects of praxis or poesis. That is, techniques are purely a 'knowhow' while science is apodictic knowledge. In that sense, as much as the techniques may serve science, they will never be on the same epistemological level.

Stiegler wants to present an alternative to this view. His starting point is that such a dichotomy does not hold up once you look at real objects. There is no thing such as a given object outside time or objects that are purely tools to a superior subject. In a sense, every object is already an object of an operation and therefore a technical one. Thus, it is evident today that technology is not a tool for science, but rather science is 'applied technology'. That is, the previous division between 'what is' and 'what could be otherwise' is no longer valid since the contemporary relation between science and technology creates a situation where the real is a function of what can be scientifically/technologically produced. Perhaps the most relevant example to the discussion here would be genetic engineering. In techno science, experimentation replaces deduction. 'Reality'

\section{Blucher}


belongs already to the past ${ }^{5}$. The question of life, i.e. the question of the relation between life and technology, is the question of becoming something since it concerns the production of life and therefore not the static image that already is but rather the constant process of turning into life.

Stiegler remarks that to combine nature and technics does not mean that one eliminates the other or that they are the same thing. It is simply to argue that their relation is of composition rather than opposition. That is, they compose together the image of life rather than competing for its true definition. It was possible to argue that life is the pure biological at the same time that it is possible to argue that life is the overcoming of the biological. Simply put, it is possible to argue that life in purely 'nature' or life is purely 'culture'. Stiegler proposed a different angle.

According to the author, existing is defined by "the chance of life as the principle of an immense process of individuation that one calls "evolution" (STIEGLER, 2007, p. 33, italics in the original). According to him, this default is the phantasm of perfection, that is, the elimination of the possibility of perfection into a real living being. This condition where there are no absolute principles of reality since all objects are technological development (and in a specific sense, artificial) is what Stiegler calls the 'great default' of the living.

It is vital to consider the role the notion of origin plays in this 'great default'. The issue of origin is often an attempt to return to what is the 'nature' of life (as opposed to its contingent

\footnotetext{
${ }^{5} \mathrm{~A}$ possible interpretation would say that Stiegler's thesis about the difference between conventional and contemporary relation between science and technology is a revolution not just in epistemology but also in ontology. I disagree with that reading. For me, Stiegler's argument just points at an ontological theme that was not epistemologically accessible before but that applies to ontology even when people thought the relation differently. In simple words, I think that his argument is valid for the relation between science and technology in general and not just for contemporary and therefore he can argue that life has always been technical.
} 
elements). In this sense, default would be the original point beyond any individualization (i.e., beyond any evolution/development into being). Stigler defends a different perspective: one where there is no original point and, instead, one originates from the process of becoming being (evolution). Rather than referring to the absolute condition of being, default would refer to impossibility of such condition: to the fact that evolution implies the absence of an essential determination or definite description. Default would be the 'fault' ${ }^{\prime 6}$ implicit in the concept of evolution. In this way, the default is without beginning because it is an anthropological a-priori (STIEGLER, 1998, p. 132).

Taking account of Stigler's concept, it is productive to turn the attention to the concept of invention. There are essentially two ways of looking at invention: one conceives it as a slow sequence of minor changes without altering the fundamental principle that considered in the long term seem to make a great change, the second considers invention as a mounting operation. This is the difference between invention and innovation. Innovation, as the first option, is adjustment; it does not replace the fundamental technical principle. In that sense, innovation is reproduction rather than evolution ${ }^{7}$. For example, the French may adapt the British railroad system to their landscape with an innovation but it would not be an invention: "Innovation accomplishes a transformation of technical system while drawing the consequences from the other systems. In other words, the rules of innovation a wholly different from those of invention. The rules of innovation are those of socialization, as analyzed by economist" (STIEGLER, 1998, p. 36)

\footnotetext{
${ }^{6}$ Stiegler is playing with the French fault which is both mistake and absence.

${ }^{7}$ It is vital to point out that reproduction is essential to evolution but they are not the same thing. The question of invention is the question of the evolution into life, that is, the fundamental changes that make life.
}

\section{Blucher}


According to the author, invention the constitution of a technical lineage whose genesis is irreducible to an absolute physical explanation. It is a process of concretization in the individual object. It is a convergence of a series of technical lines into an overcoming object of technical production:

Technical invention, not being guided by a theoretical formalism preceding practical operation, remains empirical; however, the inventive operation cannot be said to be produced by chance, for an essential part of innovation is accomplished through transfer, whereby the functioning of a structure in a technical apparatus is analogically transposed into another domain. There is, then, a combinatory genius in technical invention. This also implies the cumulative nature of technical knowledge, although in another sense than in scientific knowledge. One should speak of technological lineages, of paths through the empirical realm [empirie], of tentative groundbreakings [frayages] in the development of the potential of a technique whereby invention deploys itself. The rationality of technical invention, "situated on a determined technological line," would then be diffuse "to the extent that choices may be made, various combinations set up. For the inventor, the whole question is knowing whether the road to follow is wide or narrow" (Gille 1978, 40). As for this apparent possibility of choice, Gille speaks, with J. L. Maunoury, of "loose determinism." The difference of this from strict determinism would consist in the impossibility of anticipating technical evolution a priori, although this evolution appears necessary a posteriori[...]. The system's dynamic offers the possibility of invention, and this is what is essential to the concept of technical system: the choice of possibilities in which invention consists is made in a particular space and particular time according to the play of these constraints, which are submitted in turn to external ones (STIEGLER, 1998, p. 34-35, italics in the original)

That is, one must observe the individual in order to explain individuation: we must explore into the already concrete in order to explain concretization. The individual (the living thing) 
is what is a stake, it is the given from which we can extract what its inventions is ${ }^{8}$.

Stiegler's central argument is that the invention of the human is essentially the retention/concretization of the human condition beyond any specific human individual: a condition that is not preserved like genetic or a social identity, but that is constantly transmitted through the technics that allow the condition itself. This 'memory' remains after the individual perishes and his individuality extinguishes. In this sense, it is a past that does need to be lived (the default). At the same time, technics is always a projection into the future, a production of the condition in the world. This living memory is organized in the inorganic- it is matter that interacts with the form, i.e., a constant organization and disorganization of the organic. Perhaps, the ultimate example of this phenomenon is writing: in writing human produce/invent the human condition itself. This technical apparatus of memory retention is what allows the condition for retention itself to appear. In other words, we are writing bodies registering bodies of knowledge that we ourselves are.

This does not mean that technological development happens beyond concrete existence and actual existing objects are just the realization of this transcendental principle: as if there was an external technical spirit that comes into the world through life. Adaptation and concretization are not constantly being conditioned by an externally determined milieu, rather, those are the conditions of existence of any possible sphere of reality: the realization of a virtual possibility of any given reality in the sense of technical invention of reality- not fiction against reality but fiction as

\footnotetext{
${ }^{8}$ To superficially put it "the individual existence precedes its essence". The obvious reference to Sartre's philosophy is inevitable but I wish to ignore completely it. This does not mean that it does not exist, or is not interesting; it just means I am not concerned with it here.
} 
something that could be otherwise, i.e., as a proposal to reality ${ }^{9}$. The invention of the human is nothing more than the realization of its virtuality, which is itself conditioned on concrete adaptive processes. For example, the conditions of possibility (virtuality) of a generator are the conditions of its realization itself (invention). The prosthesis is an integral part of the body, it is an 'artificial' organ, but it functions like an organ, in fact, every organ is to some extent and 'natural prosthesis' ${ }^{10}$.

Stiegler's bottom line argument brings forth the fact that this 'default' is precisely a fault, a lacking. Thinking existence as the invention of the living invariably assumes the lack of any absolute science of being, it means considering being as the constant production of being. The image of life in such theory is not an image that demands criteria or verifiability but, rather, an investigation into the already concrete being. In other words, what activity is to be being? "Life is the conquest of mobility" (STIEGLER, 1998, p. 17). Life is not a finished project, a given and static state, instead, its default is the fault/lacking any form of completion making the living of living being an actual activity of becoming that which lacks.

Technics is essential because it is the 'mechanism' of retention. The concretization of being makes no sense without a concrete object. Every technical production is a selection, an individuation, and as such refers to the technical process of becoming: "As a 'process of exteriorization' technics is the pursuit of life by means other than life." (STIEGLER, 1998, p. 17). Returning to example of writing, it is an essential element of what is considered human since it is the retention of humanity as human culture, at the same time, culture (as an entity) is 'external' to

\footnotetext{
${ }^{9}$ An interesting question that appears here is what would be the meaning of "science-fiction" as a genre under this perspective. This is not the topic explored here; nevertheless, I think is a relevant/interesting question that his argument open the door to.

${ }^{10} \mathrm{I}$ am aware that this is a bold statement. Once I explore Jonas' theory I will return to this point concerning the body as a technical realization of being.
} 
humanity since it is an autonomous entity, i.e., does not fully belong to any set of humans as individuals or collective. Unlike the classic criticism of writing where it opposes spoken/living word as the mere apparatus of retention of the truth, Stiegler argues that writing is an elementary aspect of the human condition.

The separation of technology and life into a "who" and a "what" is profoundly misleading regardless of the stated relationship: regardless if technology is the subject and life the object made or the other way around, this configuration does not take into consideration the convergence of the two. It does not grasp the two as a common movement of existence, i.e., becoming oneself via the adaptive concretization that defines the default of existence so there is no "who" or "what", no subject or object, there is only production. The passage of one into the other is a mirage of opposition between the two (STIEGLER, 1998, p. 141). There is not interior primordial essence/principle that is affected by an exterior condition resulting in evolution; rather, the interior, i.e., what Stiegler calls the default, is exteriorization as the technical production of oneself.

It is evident that humans are not constituted uniquely by what they punctually are. Instead, any philosophy of life must take into consideration the 'becoming-organic' (STIEGLER, 1998, p. 71): how the inorganic and the organic combine into a coherent structure of living. The 'narrative' concerned with the invention of the human must take such invention as his operations simultaneously on himself and on the world-his invention of himself as the invention of the world and vice-versa. The concretization of the living is the process of becoming unified while technics is the mechanism that tends towards this unity but never is one with it ${ }^{11}$. The essential question

\footnotetext{
${ }^{11}$ Stiegler uses the term "technological maieutics" (STIEGLER, 1998, p. 75 and 142) to describe this process. Here I will not
} 
Stiegler leaves is how to properly cope with this:

problem arising here is that the evolution of this essentially technical being that human is exceeds the biological, although this dimension is an essential part of the technical phenomenon itself, something like an enigma. The evolution of the "prosthesis", not itself living, by which the human is nonetheless defined as a living being, constitutes the reality of the human's evolution, as if, with it, the history of life were to continue by means other than life: this is the paradox of the living being characterized in its forms of life by the nonliving- or by the traces that its life leaves in the nonliving. There is consequently an evolutionary determinism that is not only biological but also, for reasons we have seen earlier, quasi-zoological (STIEGLER, 1998, p.50).

\section{The question of life:}

Jonas in his book The Phenomenon of Life provides a philosophical theory aimed at solving the biological issue. According to him, if Biology and Philosophy share the common objective of explaining life, the two enterprises cannot be contradictory or even opposed. Modern though created the dualistic situation where life is essentially double and at best coincides with itself. For example, if we divide life into matter and spirit we can either reduce one into the other or at best argue that they coincide despite being absolutely different. In the first configuration we would not even have a coherent thought since both materialism and idealism fails in the sense that it is impossible to deny the opposite entity (matter or spirit) any ontological value (JONAS, 1966,

explore the deeper meaning of this but I imagine that the term itself already adds to the image I portrayed. 
The Invention of Human: Biology and technology as existence

p. 88). He calls this configuration the Cartesian image of the world. In its most prominent development it argues that the body is just the machine of the soul: every organ is considered a tool without considering its purpose as part of an overall configuration living form:

This is not just an additional aspect of them, or an optional mode of interpretation: it is their own teleological nature. However complete the physicochemical analysis of the composition of the eye and the process attending its stimulation may be, no account of its construction and functioning is meaningful without relating of it to seeing. (JONAS, 1966, p. 90)

In this way, Jonas argues that modern thought cannot conceive life because it always already assumes death. In the dualistic picture, the body is always dead matter. Even when a spirit is proposed, it is always an absolute spirit that has no connection to concrete life and therefore to reality (as in idealism). The author point to the fact that it is impossible reflect on life if the presupposition labels the body as dead (purely matter). To think the body as a fully prearranged mechanism is to think it as a dead structure that at best houses a mind and at worst this mind is just an illusion. Jonas argues that conceiving the body within this configuration is equivalent to forgetting the most basic principle behind life: life itself. The greatest illustration of this model is the theory that all there is to mind are chemical reactions: all our emotions and thoughts are purely static combination of chemical molecules- happiness in a pill as in the psychiatric promise. If mind can be reduced to a formula of material combination of elements, it is not a living thing: "This is because "unraveling" means reduction to the elementary, which is "inorganic", that is, lifeless, [...]" (JONAS, 1966, p. 87).

To thoroughly reflect on this issue, Jonas proposed that we imagine god as a 
mathematician. The idea is that given the mechanism of life it would be possible to imagine god as the supreme engineer who planned and observes the world according to a formula. However, there is the question of what would he see? Jonas mentions the different answer to this question, but the most interesting/relevant answer is the modern version since it stands on the problematic perspective held today. According to it, the modern god would either see two completely separate objects that coincide with each other, or the unity of these two objects in a common process of realization.

Jonas wished to take the second option and he names the process that unites both aspects of being metabolism. Metabolism points precisely to the fact that there is no static picture of life:

I refer to its metabolism, its exchange of matter with the surroundings. In this remarkable mode of being, the material parts of which the organism consists at a given instant are the penetrating observer only temporary, passing contents whose joint material identity does not coincide with the identity of the whole which they enter and leave, and which sustains its own identity by the very act of foreign matter passing through its spatial system, the living form. (JONAS, 1966, p. 75-76).

Life is not equivalent to the static state of either materiality or spirituality. Life is the process of living, the process of exchanging between the inwardness and the external ${ }^{12}$. It may

\footnotetext{
${ }^{12}$ Jonas uses the concept of 'inwardness' to refer to this notion of existence/life/being. In order to avoid further complicating the dialogue between the theories I chose to use the notion of Being. Obviously, there are differences between the theories and their usage of these concepts but since my objective is looking at the common aspect, I found it more productive to use one concept throughout the argument. Still I strongly believe that my usage of the concept is extremely loyal to Jonas' original intention in 'inwardness'. That is, thinking Being as becoming and using a notion that does sit on the line of mind-body, subjectobject...So, given this I find it safe to say that any usage of Being could easily be replaced with 'inwardness' (in order to be more 'faithful' to the original) without affecting the content of the text.
} 
seem complicated, but in common language: life as the process of living means that life is nothing beyond the actual process of living, that is, the body is the constant metabolism, the constant exchange with the environment that defines bodily activity- life is always breathing, eating, urinating, etc. The body is always decomposing and recomposing itself. The food eaten becomes the material composing the body. At one point, every cell that once composed a body is no longer part of this same body and it undeniably remains. It remains the same body precisely because it is no longer what it once was: because it becomes itself via its metabolism. In fact, there is no central core that coordinates the whole project; there is no remaining part that is essential to the process. The living body is equal to the metabolizing body and so life becomes equal to metabolism.

At this point, it is essential to close in on Jonas' argument in order to avoid a problematic understanding of the picture. A machine can also be considered a metabolizing body. A motor receives fuel and combusts it to create energy that creates movement. If the living body is equal to the motor, one does not overcome the Cartesian dualism ${ }^{13}$. However, the body is not like a machine. The combustion process does not affect the machine or necessary to it: it is possible to think of a standstill machine or an active machine but this logic does not apply to the body. The machine is just the space where the process happens; it is not the process itself. The body, on the other hand, is integrally determined by metabolism, metabolism is not a separate activity that incidentally occurs in the body- metabolism defines the body. Jonas' example of the fuel best illustrates this, the motor combusts fuel to generate heat or kinetic energy while the body metabolizes food/air/etc. to produce itself rather than just create movement for an external entity.

\footnotetext{
${ }^{13}$ Since it would mean that, the body is just the machine for the soul.
} 
Yonathan Listik

The energy created becomes the energy of the body; it becomes the body and not just an effect or a residue of the process (JONAS.1966, p. 76 note 13).

In this sense, Jonas is arguing that being alive is nothing more than the mere configuration of the living organism. Again, not exclusively in the sense of his sheer materiality, but, instead, in the sense of his constant activity as an organism, i.e., in his constant metabolism. In his constant relation with the external, he becomes who he is. There is not static living individual, rather, just like a wave, it is moving in constant exchange. It makes itself at the same time that it leaves itself- there is not singular moment in which one can pinpoint the wave perse in its absolute sense, in the same way, the living body only makes sense in its metabolizing and not as a final and definite categorization.

The issue of technology in the model developed by Stiegler appears here in the sense that the metabolizing mechanism of living is the technological mechanism of the invention of body. The bodily functions are the production living functions. Neither in the materialistic sense that all can be reduced to matter nor in the idealistic sense that that the body performs the actions dictated by an absolute mind, but, instead, in the sense that the condition that allows (not in the sense of a formal permission but in the sense of giving possibilities) being to be as metabolism are the conditions of adaptation and concretization of the body through an evolutive process. The invention of the human is the invention of the human capacity to cope with his environment in a certain way that does not exclude him from the environment but, instead, inserts him in the ecosystem of exchanges.

Under this perspective, the human body is not a tool for the human soul. It is not the machine where the process of living occurs but that is not related to the actual process of living. It 
is not the technology to a science in the old picture. Instead, Jonas' theory explores the idea that the body is living: its technology is living technology since the body is the apparatus of its realization as a body. Materiality is not external to the human condition serving exclusively as a tool for its realization. The sphere of technological possibilities does not determine the essence of being as in an external factor that determines/imposes the conditions of living. Techne is living techne because living is exactly the creation of the possibilities of such technological conditions of living: it is the constant invention of the living condition or in Jonas' words metabolism. The metabolizing body is the body that uses its technical possibilities to create the technical conditions of itself. In a superficial (but not wrong) sense, the protein that the stomach digests becomes the protein that the stomach is. Jonas' project attempt to cope with Biology, in that sense, goes in the same line as the technological question proposed by Stiegler: thinking the body as the space of living and not as a tool of living.

It is possible to think of the body as a collection of different organs each performing its function but then the question would be to whom are they performing. If they are performing for their own individual self-maintenance, one has simply avoided the question since it would still be necessary to explain the configuration they form. The body does not function as a catalogue of separate organs; rather, it has a common purpose/performance. The answer to the question "what is the body?" is not a list of all its organs. On the other hand, organs are not tools/machines for the survival of a bigger entity of whatever sort.

There is no contingency in the body, as much as you can replace certain organs (the question of prosthesis); each organ is an integral part of the body. There is nothing to the body beyond the organs that form it. There is no spirit that comes into the body-machine in order to add

\section{Blucher}


movement to it. Jonas' metabolic answer demands that we look at organs (the body) as a technological entity and therefore as natural prosthesis, not as tools for a greater purpose, rather as affirmation of the technicity that being invariably is. In Stiegler's words, Jonas shows that the living body in its metabolism performs the lack that it invariably is. The body is always the production of itself. That is, the body is always reproducing. The old image of nature as a given and techne as contingent is replaced by a Biology where the real is a function of the possible. The real/natural becomes a function of what the self-production of the body makes of itself.

The invention of the human does not refer to a moment in the past where the human was invented as an object. It refers to the process constantly taking place in which the human perpetually appears as the human: becoming/evolving into the human from the already human.

\section{Bibliography:}

BERGSON, Henri . Creative Evolution Trad: Arthur Mitchell New York: Modern library, 1944. Print.

DELEUZE, Gilles. Bergsonism. New York: Zone Books, 1988. Print.

JONAS, Hans. The Phenomenon of Life: toward a Philosophical Biology; Essays. New York: Harper \& Row, 1966. Print.

KOŁAKOWSKI, Leszek. Bergson. Oxford: Oxford University Press, 1985. Print.

POPPER, Karl R. Unended Quest: an Intellectual Autobiography. La Salle, IL: Open Court, 1976. Print.

STIEGLER, Bernard. Technics and Time. Stanford, CA: Stanford University Press, 1998. Print. . "Technoscience and Reproduction." Parallax 13.4 (2007): 29-45. Web. 